\title{
Effect of Insulin-Induced and Fasting Hypoglycemia on Perinatal Hypoxic-Ischemic Brain Damage
}

\author{
JEROME Y. YAGER, ${ }^{1}$ DANIEL F. HEITJAN, JAVAD TOWFIGHI, AND ROBERT C. VANNUCCI \\ Department of Pediatrics (Pediatric Neurology) [J.Y.Y., R.C.V.] and Pathology (Neuropathology) [J.T.] and \\ Centre for Biostatistics and Epidemiology [D.F.H.], The Pennsylvania State University School of Medicine, The \\ Milton S. Hershey Medical Center, Hershey, Pennsylvania 17033
}

\begin{abstract}
Experiments in adult animals have indicated that hyperglycemia accentuates whereas hypoglycemia ameliorates hypoxic-ischemic brain damage. To determine whether hypoglycemia is protective or deleterious to the perinatal brain subjected to hypoxia-ischemia, 7-d postnatal rats were rendered hypoglycemic either by receiving an s.c. injection of insulin or fasting for $12 \mathrm{~h}$. All rat pups underwent unilateral common carotid artery ligation followed by exposure to $8 \%$ oxygen-balance nitrogen at $37^{\circ} \mathrm{C}$ for $\mathbf{2} \mathrm{h}$. Control animals (no insulin or fasting) received s.c. injections of normal saline. Mean blood glucose concentrations were $5.4 \pm 0.1,4.3 \pm 0.2$, and $3.4 \pm 0.1 \mathrm{mmol} / \mathrm{L}$ for control, insulin, and fasted animals, respectively. Blood $\beta$ hydroxybutyrate concentrations were identical $(0.5 \pm 0.1$ $\mathrm{mmol} / \mathrm{L}$ ) for control and insulin-treated animals, but more than doubled in concentration in the fasted animals $(p<$ 0.001). Mortality rates during hypoxia-ischemia were higher in the insulin-treated animals $(30 \%)$ than in either the fasted $(4 \%)$ or control $(0 \%)$ animals $(p<0.05)$. Fasted animals showed a significant reduction in hypoxic-ischemic brain damage as compared with either the insulin-treated or control animals. Insulin-treated animals were not significantly different from controls. The findings indicate that 1) insulin induced hypoglycemia does not provide a protective effect on perinatal hypoxic-ischemic brain damage, as in adults; and 2) fasting adequate to produce hypoglycemia and ketonemia improved neuropathologic outcome. (Pediatr Res 31: 138-142, 1992)
\end{abstract}

Hyperglycemia accentuates the brain damage produced by cerebral ischemia in adult animals and humans, the mechanism of injury presumably resulting from enhanced tissue lactic acid accumulation and cellular acidosis (1-5). On the other hand, mild to moderate hypoglycemia before or after cerebral ischemia may be protective (6-8). Nedergaard and Diemer (9) assessed the effect of varying glucose concentrations on focal cerebral ischemia in adult rats and found a reduction of infarct size in those animals rendered hypoglycemic even to glucose concentrations as low as $2 \mathrm{mmol} / \mathrm{L}$, when compared with normoglycemic animals.

Received March 5, 1991; accepted September 27, 1991.

Correspondence: Robert C. Vannucci, Professor and Head, Division of Pediatric Neurology, Milton S. Hershey Medical Center, 500 University Drive, Hershey, PA 17033.

Supported by Grant HD 19913 from the National Institute of Child Health and Human Development (R.C.V.) J.Y.Y. is the recipient of a Medical Research Council of Canada Fellowship Award.

' Current address: Royal Uni Hospital, Department of Pediatrics, Saskatoon, Saskatchewan, Canada S7N OXO.
In contrast, hyperglycemia does not accentuate hypoxicischemic brain damage in immature animals but instead may provide partial protection. Glucose administration before hypoxia-ischemia prolongs the survival of immature rats (10). Furthermore, glucose supplementation has been shown to reduce brain damage when given after forebrain ischemia in immature rats (11).

Hypoglycemia frequently accompanies perinatal asphyxia, especially in small for gestational age newborn infants (12). Because the effect of combined hypoglycemia and asphyxia on the immature human brain is unknown, we assessed the extent to which hypoglycemia influences neuropathologic outcome in an animal model of perinatal hypoxic-ischemic brain damage.

\section{MATERIALS AND METHODS}

All studies used pregnant Wistar rats purchased from a local breeder (Charles River Laboratories, Wilmington, MA). Dams were individually housed and fed ad libitum. Rat pups, delivered vaginally, were maintained with their dams until the time of experimentation.

Three experimental groups (control, insulin, and fasting) were chosen to assess the effect of mild to moderate hypoglycemia on neuropathologic outcome after hypoxia-ischemia. Hypoglycemia was produced by either fasting for $12 \mathrm{~h}$ or by the s.c. injection of insulin.

Preliminary studies. Preliminary studies were performed to ascertain both the concentration of insulin and the interval from injection to the anticipated onset of hypoxia-ischemia required to produce mild to moderate hypoglycemia (blood glucose $=$ 2.5-5.0 mmol/L). Seven-d postnatal rat pups were individually injected s.c. with differing concentrations of bovine/pork regular insulin $(0.5-10.0 \mathrm{U} / \mathrm{kg}$ ) (Eli Lilly, Indianapolis, IN), after which the animals were killed by decapitation at intervals ranging from $30 \mathrm{~min}$ to $3 \mathrm{~h}$. Blood samples were obtained from the severed neck vessels, the plasma separated by centrifugation, and plasma glucose concentrations determined on a microglucose analyzer (Beckman Glucostat, Beckman Instruments, Fullerton, CA).

To determine the length of time required for fasting immature rats to attain blood glucose concentrations comparable to the values attained in animals receiving s.c. injections of insulin, 7d-old rat pups were separated from their dams for up to $30 \mathrm{~h}$. Animals were killed at increasing intervals of fasting, and plasma glucose concentrations determined as described above.

The results of these preliminary studies then were used to design a definitive experimental protocol.

Experimental protocol. Seven-d postnatal rats were fasted by separating them from their dams and maintaining them at nesting temperature $\left(34-35^{\circ} \mathrm{C}\right)$ under a warming lamp for $12 \mathrm{~h}$. Littermates received an s.c. injection of $0.5 \mathrm{U} / \mathrm{kg}$ insulin mixed to a total volume of $0.1 \mathrm{~mL}$ with normal saline $90 \mathrm{~min}$ before 
hypoxia-ischemia. After the insulin injections, the rat pups were placed under the warming lamp and also separated from their dams. Control littermates remained with their dams until time of exposure to hypoxia-ischemia. Both the fasted and the control rat pups received s.c. injections of $0.1 \mathrm{~mL}$ normal saline $90 \mathrm{~min}$ before exposure to hypoxia-ischemia. All rat pups were weighed at $6.5 \mathrm{~d}$ of postnatal age (before fasting) and again before the injection of either insulin or normal saline.

Induction of hypoxia-ischemia. At 7 postnatal d, all rat pups underwent permanent unilateral (right) common carotid artery ligation through a midline neck incision under halothane anesthesia ( $4 \%$ induction; $1 \%$ maintenance). The operative procedure lasted no longer than $10 \mathrm{~min}$, after which the pups were allowed to recover for $3 \mathrm{~h}$ either under the warming lamp (fasted) or with their dams (insulin and controls). Unilateral common carotid artery ligation alone does not result in brain damage (13). Hypoxia-ischemia was induced by placing one littermate pup from each group (control, fasted, and insulin), previously matched for weight, into $500-\mathrm{mL}$ glass jars (three per jar) maintained in a water bath at a constant temperature of $37^{\circ} \mathrm{C}$. Thereafter, $8 \%$ oxygen-balance nitrogen was delivered through the jars for $2 \mathrm{~h}$ via inlet and outlet portals. After the hypoxic exposure, surviving rat pups were allowed to recover for $15 \mathrm{~min}$ in open jars and then were returned to their dams and reared until age $30 \mathrm{~d}$ of postnatal age.

Neuropathologic analysis. At 30 postnatal d ( $23 \mathrm{~d}$ of recovery), all animals were injected s.c. with a lethal dose of pentobarbital $(100 \mathrm{mg} / \mathrm{kg})$, and their brains were rapidly removed from the skulls and placed in solutions of formaldehyde, acetic acid, and methanol (1:1:8). Two observers, blinded to the experimental manipulation, graded the extent of brain damage in each animal by ranking each brain from least to most damaged. Brains also were grouped according to the severity of damage. Briefly, individual brains were grouped into one of four categories as indicated in Figure 1. Normal-appearing brains refer to those in which there was no discernable difference in the size of the two cerebral hemispheres; mild damage describes brains in which the lateral-posterior aspect of the right hemisphere was atrophic; moderate damage indicates brains in which both the anterior and posterior aspects of the right hemisphere were atrophic; and severe damage refers to the total destruction, by prior infarction, of the cerebral cortex in the distribution of the middle cerebral artery of the right hemisphere.

Brains with moderate and severe damage as assessed by neuropathologic ranking were subjected to histologic analysis to ascertain: 1) whether the nature and distribution of brain damage incurred by hypoxia-ischemia alone differs from that which occurs with the additive effect of mild to moderate hypoglycemia and 2) the incidence of brain infarction as compared with selective neuronal necrosis in each of the experimental groups. Brains with mild damage as assessed by rank scoring have previously been shown to display only selective neuronal necrosis (14). The brains were transected coronally at the level of the anterior commissure and mammillary bodies and also through the midbrain, pons, and medulla. Histologic sections were prepared and stained with hematoxylin and eosin and selected sections with glial fibrillary acidic protein. Infarction was defined as pan-necrosis of all tissue elements with cystic formation.

Biochemical analyses. Blood $(0.005 \mathrm{~mL})$ for determination of glucose and $\beta$-hydroxybutyrate was obtained by tail snip from each pup immediately before the onset of hypoxia-ischemia. Blood specimens were diluted $1: 10$ with $0.5 \mathrm{M}$ perchloric acid. Samples were kept at $-4^{\circ} \mathrm{C}$ until analyzed by specific enzymatic, fluorometric techniques. Concentrations of glucose were determined as described by Lowry and Passonneau (15). $\beta$-hydroxybutyrate was analyzed by the method of Williamson and Mellanby (16).

Statistical analyses. Mortality data were analyzed using Fisher's exact test. Neuropathologic rank scoring was assessed using nonparametric statistical methods, the Kruskal-Wallis test for

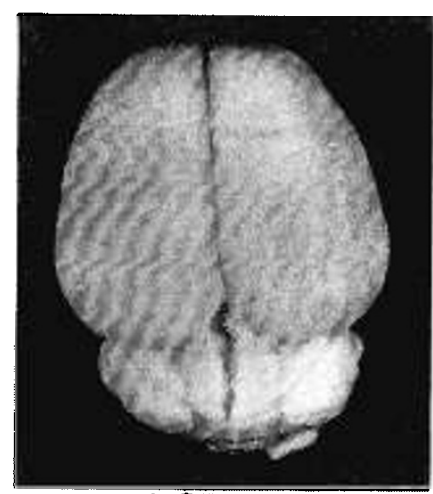

NORMAL

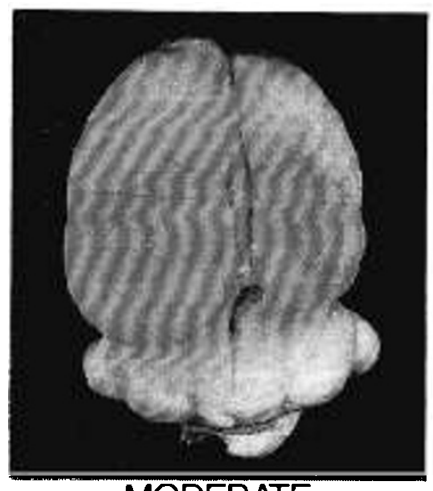

MODERATE

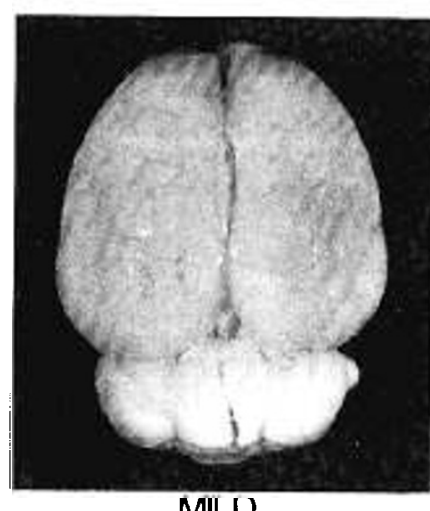

MILD

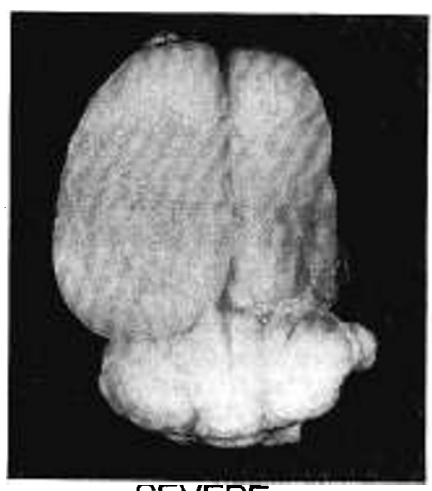

SEVERE
Fig. 1. Dorsal view of representative rat brains from each of four distinct categories: normal = equal size of the two cerebral hemispheres; mild $=$ atrophy of lateral-posterior aspect of right hemisphere; moderate $=$ atrophy of anterior and posterior aspects of right hemisphere; and severe = destruction by prior infarction of the cerebral cortex of the right hemisphere.

comparing all three treatment groups simultaneously, and the Mann-Whitney test for pairwise comparisons of the three groups. $t$ tests and multiple repression analyses were also used where appropriate.

\section{RESULTS}

Preliminary studies. The s.c. injection of insulin in 7-d postnatal rats at doses ranging from 0.5 to $10.0 \mathrm{U} / \mathrm{kg}$ resulted in progressively decreasing plasma glucose concentrations to a low of $1 \mathrm{mmol} / \mathrm{L}$ (Fig. 2). Increasing the dose of insulin to $15 \mathrm{U} / \mathrm{kg}$ did not result in a further decline in plasma glucose. Trough plasma glucose values were reached by $90 \mathrm{~min}$ after insulin injection, after which glucose concentrations remained stable for an additional 30-60 min.

Fasting of rat pups for up to $30 \mathrm{~h}$ resulted in a progressive decrease in plasma glucose concentrations during the first $12 \mathrm{~h}$, after which glucose values plateaued for $6-12 \mathrm{~h}$ and then returned toward the normoglycemic concentration (Fig. 3).

Seven-d rat pups injected with $10 \mathrm{U} / \mathrm{kg}$ insulin and exposed to $8 \%$ oxygen without prior common carotid artery occlusion exhibited a mortality rate of $20 \%$ during $3 \mathrm{~h}$ of hypoxia. Survival was substantially reduced when rat pups injected with insulin underwent both carotid artery ligation and hypoxia for $3 \mathrm{~h}$ (hypoxia-ischemia). The injection of as little as $0.5 \mathrm{U} / \mathrm{kg}$ insulin resulted in a $70 \%$ mortality; 2 and $5 \mathrm{U} / \mathrm{kg}$ insulin resulted in 85 and $90 \%$ mortalities, respectively. To minimize mortality, a $0.5-$ $\mathrm{U} / \mathrm{kg}$ insulin injection was combined with a shorter length of exposure to hypoxia-ischemia $(2 \mathrm{~h})$ for the definitive study.

Definitive study. There was no difference among treatment groups in the mean weights of the rat pups before the onset of the experimental protocol. During $12 \mathrm{~h}$ of fasting, rat pups lost an average of $0.34 \mathrm{~g}$ compared with the control and insulin- 


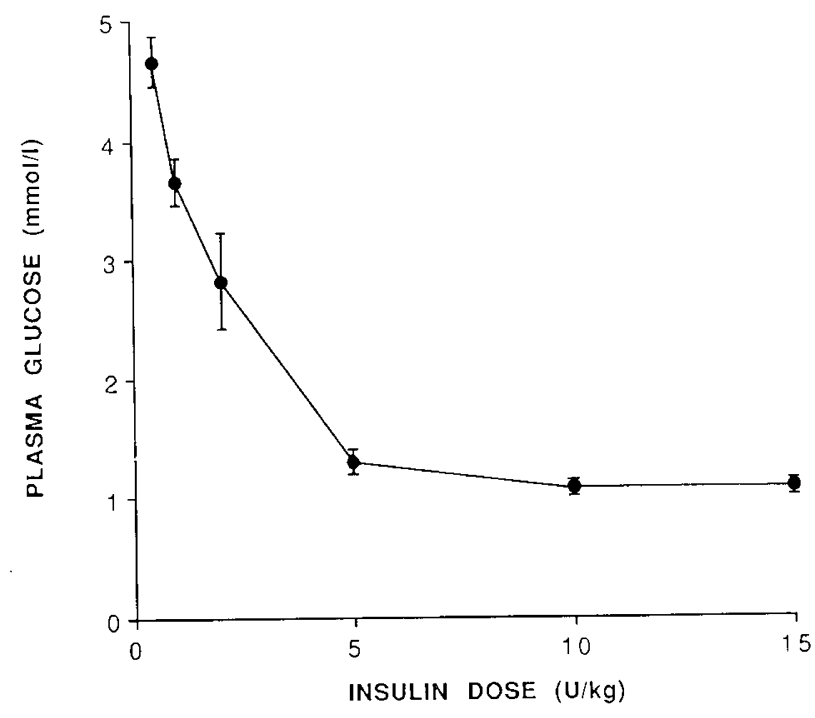

Fig. 2. Plasma glucose concentrations with increasing doses of insulin. Seven-d postnatal rat pups were injected s.c. with insulin 90 min before the blood glucose determination. Values represent means \pm SEM for three to four animals.

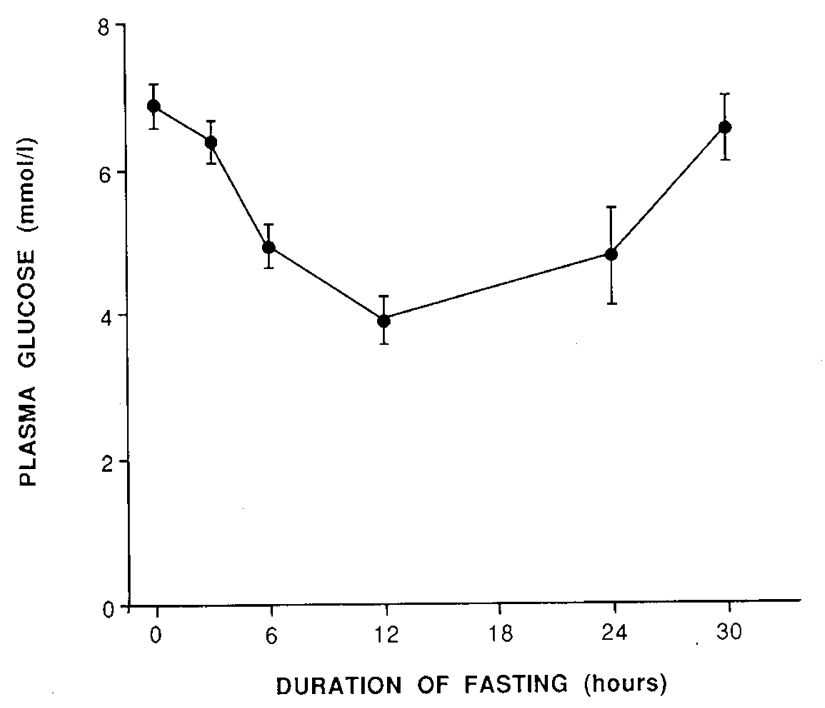

Fig. 3. Plasma glucose concentrations with increasing intervals of fasting. Rat pups of $6.5 \mathrm{~d}$ postnatal age were separated from their dams and maintained under a warming lamp at $34-35^{\circ} \mathrm{C}$ environmental temperature. Values represent means \pm SEM for four animals.

treated animals, which gained 0.24 and $0.19 \mathrm{~g}$, respectively ( $p=$ $0.05)$.

Whole blood concentrations of glucose and $\beta$-hydroxybutyrate of all experimental animals (survivors and nonsurvivors) are shown in Table 1 . Glucose values differed significantly among the three groups, control animals having the highest concentration of glucose and fasted rat pups having the lowest.

Insulin-treated animals exhibited blood $\beta$-hydroxybutyrate levels virtually identical to control, despite significantly lower concentrations of blood glucose (Table 1). Fasting for $12 \mathrm{~h}$ resulted in a more than doubling of the blood $\beta$-hydroxybutyrate concentration.

Mortality rates during hypoxia-ischemia for the three experimental groups are shown in Table 2. Eight of 27 (30\%) of the insulin-treated newborn rats died during the $2 \mathrm{~h}$ of hypoxiaischemia. In contrast, there were no deaths in the control group, and only one of $24(4 \%)$ fasted rat pups died. An inverse correlation appeared to exist between the blood glucose concentration and mortality in the insulin-treated animals. Specifically,
Table 1. Blood glucose and $\beta$-hydroxybutyrate concentrations*

\begin{tabular}{ccc}
\hline Treatment & $\begin{array}{c}\text { Glucose } \\
(\mathrm{mmol} / \mathrm{L})\end{array}$ & $\begin{array}{c}\beta \text {-Hydroxybutyrate } \\
(\mathrm{mmol} / \mathrm{L})\end{array}$ \\
\hline Control $(n=25)$ & $5.37 \pm 0.13$ & $0.54 \pm 0.05$ \\
Insulin $(n=27)$ & $4.30 \pm 0.17 \dagger$ & $0.52 \pm 0.05$ \\
Fasting $(n=24)$ & $3.38 \pm 0.12 \dagger \ddagger$ & $1.17 \pm 0.05 \dagger \ddagger$ \\
\hline
\end{tabular}

* Values represent mean \pm SEM for the numbers of animals in parentheses. Insulin $(0.5 \mathrm{U} / \mathrm{kg})$ was injected s.c. $90 \mathrm{~min}$ before hypoxiaischemia. Other rat pups were fasted for $12 \mathrm{~h}$ before hypoxia-ischemia. All blood samples were obtained from the tail immediately before hypoxia-ischemia.

$\dagger p<0.001$ compared with control.

$\ddagger p<0.001$ compared with insulin.

Table 2. Mortality rates during hypoxia-ischemia of control,

\begin{tabular}{lccc}
\multicolumn{4}{c}{ insulin-treated and fasted } \\
& Control & Insulin & Fasting \\
\hline Survived & 25 & 19 & 23 \\
Expired & 0 & $8 \dagger$ & 1 \\
Total & 25 & 27 & 24 \\
\hline
\end{tabular}

* Values represent numbers of animals in each experimental group.

$\dagger p<0.05$ compared with both control and fasted animals by Fisher's exact test.

the lower the blood glucose during hypoxia-ischemia, the greater the mortality. However, the small number of animals that expired by varying blood glucose concentrations precluded statistical analysis.

Brains of surviving rat pups from all three groups were ranked by two examiners from 1 to 67 according to the extent of brain damage at 30 postnatal $\mathrm{d}$. The higher the rank score, the greater the tissue injury seen in the cerebral hemisphere ipsilateral to the common carotid artery ligation. The mean rank scores for the insulin-treated and control animals were $46 \pm 3$ and $36 \pm 4$, respectively, the insulin $(p<0.001)$ and control $(p<0.05)$ groups both displaying significantly greater brain damage than the fasted animals (mean rank score $=22 \pm 3$ ). Neuropathologic outcome tended to be worse in the insulin-treated animals compared with controls, but not significantly $(p=0.06)$.

Multiple regression analyses of the rank scores of brains in all groups versus glucose and $\beta$-hydroxybutyrate revealed an inverse correlation only between $\beta$-hydroxybutyrate and the extent of brain damage $(p<0.001)$. Multiple regression analyses of brain damage versus glucose and $\beta$-hydroxybutyrate within groups displayed an inverse correlation between $\beta$-hydroxybutyrate and the extent of brain damage only in the insulin-treated animals. Specifically, the higher the $\beta$-hydroxybutyrate level, the less the severity of brain damage. No correlation existed between glucose concentration and rank score in any of the treatment groups.

The neuropathologic alterations that characterized the different experimental groups revealed no difference in the distribution of the injury in similarly damaged brains when compared by histologic examination. Cerebral hemispheres contralateral to the carotid artery ligation were normal in all groups. Obvious by both visual inspection and microscopic examination, however, was the reduction in the number of brains exhibiting cystic infarcts in those animals that were fasted when compared with either control or insulin-treated groups (Table 3). Only two brains of the fasted animals displayed cystic infarction compared to seven brains in the insulin group and eight brains in the control group $(p<0.05)$.

\section{DISCUSSION}

The results of the present investigation show evidence for a protective role of fasting in perinatal hypoxic-ischemic brain damage. In the immature rat, fasting adequate enough to stimulate ketone body production reduced the extent of brain damage 
Table 3. Severity of neuropathologic alterations resulting from hypoxia-ischemia in control, insulin-treated and fasted 7-d postnatal rats*

\begin{tabular}{lccc}
\hline Category & Control & Insulin & Fasting \\
\hline Noninfarct & $17(68 \%)$ & $12(63 \%)$ & $21(91 \%)$ \\
Infarct & $8(32 \%)$ & $7(37 \%)$ & $2(9 \%) \dagger$ \\
Total & 25 & 19 & 23 \\
\hline
\end{tabular}

* Values represent numbers of brains in each experimental group with percentages in parentheses. Comparison of number of brains exhibiting cystic infarction by microscropic examination (infarct) $v s$ selective neuronal necrosis (noninfarct) in each treatment group.

$\dagger p<0.05$ compared with both control and insulin-treated rat pups by one-tailed Fisher's exact test.

resulting from hypoxia-ischemia concurrent with mild hypoglycemia. On the other hand, insulin administration substantially increased mortality during hypoxia-ischemia and enhanced brain damage compared with fasted animals despite less severe hypoglycemia in the insulin-treated animals. The difference in neuropathologic outcome between fasted and insulin-treated animals emphasizes a fundamental dissimilarity in substrate use between the immature and adult brain. The immature brain has a diminished capacity for glucose uptake from blood and utilization compared with its adult counterpart (17-19). Both fetal and newborn animals use alternate substrates, including lactate, pyruvate, and ketone bodies, which supplement glucose to support oxidative metabolism (20-23). Several studies suggest a similar developmental pattern of substrate use in the human infant (2426).

The near $100 \%$ mortality seen in immature rats receiving 5 $\mathrm{U} / \mathrm{kg}$ insulin and exposed to unilateral common carotid artery occlusion combined with $8 \%$ oxygen contrast with the $20 \%$ mortality in similarly hypoglycemic animals that were subjected to systemic hypoxia without superimposed cerebral ischemia. The increased mortality rate of the rat pups rendered hypoxicischemic most likely relates to severely reduced substrate delivery to vital brainstem structures, leading in turn to compromised respiratory function, apnea, and associated cardiovascular collapse. In this regard, unilateral common carotid artery ligation and superimposed hypoxia in the immature rat lower blood flow not only to the cerebral hemisphere ipsilateral to the arterial occlusion but also to the brainstem (27), and occasionally ischemic neuronal alterations are seen within specific brainstem regions as well (28). In adult rats, the combination of forebrain ischemia and insulin-induced hypoglycemia leads to brainstem damage, whereas normoglycemic animals rendered similarly ischemic do not exhibit brainstem pathologic changes (29). Using a methylmethacrylate infusion to produce vascular casts, Wellens et al. (30) found that the predominant source of blood flow to the brainstem of rodents is derived from the paired internal carotid arteries rather than from the vertebro-basilar arterial system.

The more extensive brain damage exhibited by insulin-treated rat pups compared with fasted animals is explained by the associated reduction in total substrate supply to the brains of the insulin-treated animals. Insulin, an anabolic hormone, inhibits the production of ketone bodies while decreasing systemic glucose concentrations. Although not specifically measured in this study, lactate, a fuel readily metabolized by the newborn brain $(31,32)$, is either unchanged or reduced in blood under conditions of insulin-induced hypoglycemia (33). In contrast, fasting promotes ketone body formation, concentrations of which increase in blood as glucose levels decline. Given the capability of the immature brain to use ketone bodies relative to the adult, total substrate supply to the immature brain during fasting is enhanced.

Insulin receptors are known to exist in immature rat brain (34-36). Accordingly, an alternative hypothesis to explain the heightened hypoxic-ischemic sensitivity of immature rats receiv- ing insulin compared with fasted animals would relate to a direct effect of the hormone on brain metabolism. Several lines of evidence suggest a direct inhibitory effect of insulin on synaptosomal norepinephrine uptake in both fetal and adult neuronal cell cultures $(37,38)$. Catecholamines, and in particular norepinephrine, released from the locus ceruleus of the brainstem have a protective effect on ischemic neuronal necrosis (39-41). It follows that blockage of norepinephrine transmission by insulin would enhance ischemic injury. However, it must be emphasized that little is known regarding the effect of insulin per se on the immature rat in vivo.

The improved hypoxic/ischemic survival of fasted compared with either normoglycemic animals $(42,43)$ or insulin-induced hypoglycemic animals (present study; 42) is likely the result of enhanced endogenous production of ketone bodies, the concentration of $\beta$-hydroxybutyrate in fasted rat pups being more than double the values found in the other two groups. The results find precedent in a recently published study that showed a prolonged hypoxic/anoxic survival of immature mice administered $\beta$-hydroxybutyrate (44). Investigations in adult rats subjected to hypoxia-ischemia also have shown reductions of cerebral edema, improved energy metabolism, and decreased neurologic deficits after induced ketosis $(45,46)$. Indeed, the present findings are entirely consistent with the original data of Myers and Yamaguchi (1), which showed improved neurologic outcome of fasted monkeys subjected to cardiac arrest compared with either fed or glucose-infused animals.

The mechanism whereby ketone bodies protect the brain from hypoxic/anoxic mortality and hypoxic-ischemic brain damage presumably relates to the substrate's ability to undergo oxidative decarboxylation to provide reducing equivalents to mitochondria for energy production. Immature animals, and especially rodents, are well adapted to benefit from the effect of ketone bodies for the following reasons. First, the capacity of the immature bloodbrain barrier to transport ketone bodies from blood into brain is 3-fold greater than the capacity for glucose transport (47). Second, those enzymes linked to ketone body metabolism in brain display a rapid increase in activity after birth and a subsequent decline after weaning in contrast to the pattern displayed by the key enzymes of glycolysis (phosphofructokinase, hexokinase, and pyruvate dehydrogenase), whose activities increase slowly with advancing maturity $(48,49)$. Third, the model to produce hypoxic-ischemic brain damage used in the present study represents a model of incomplete ischemia, whereby substrate delivery to the vulnerable regions of brain is curtailed but not completely disrupted (26). Lastly, mitochondria actually become oxidized rather than reduced during the course of hypoxia-ischemia in the immature rat, suggesting that a deficiency of substrate availability to produce reducing equivalents for energy production is a major contributor to the genesis of brain damage (50). Accordingly, any improvement in substrate delivery afforded by increased blood concentrations of ketone bodies should reduce the severity of perinatal hypoxic-ischemic brain damage. Biochemical investigations to verify or deny this hypothesis are in progress.

Selective neuronal necrosis denotes brain damage that is restricted to neurons with sparing of glia and blood vessels, whereas infarction denotes damage to all tissue elements. The marked reduction in the incidence of brain infarction seen in the fasted immature rats subjected to hypoxia-ischemia is important in this context. Recent data from fetal cell cultures of rat brain neurons, astrocytes, and oligodendroglia suggest that both astrocytes and oligodendrocytes use ketone bodies and fatty acids more efficiently than do neurons, which better use glucose (51). The immature brain, which has a greater capacity to incorporate and use ketone bodies than adult brain (52), when exposed to high concentrations of acetoacetate and $\beta$-hydroxybutyrate before and during hypoxia-ischemia may be capable of preserving glial populations for prolonged periods, thereby reducing the likelihood that infarction will occur. 
Acknowledgments. The authors thank Robert M. Brucklacher and Cathy Housman for their expert technical assistance.

\section{REFERENCES}

1. Myers RE, Yamaguchi S 1977 Nervous system effects of cardiac arrest in monkeys. Preservation of vision. Arch Neurol 34:65-74

2. Welsh FA, Ginsberg MD, Rieder W, Budd WW 1980 Deleterious effect of glucose pretreatment on recovery from diffuse cerebral ischemia in the cat. II. Regional metabolite levels. Stroke 11:355-363

3. Pulsinelli WA, Waldman S, Rawlinson D, Plum F 1982 Moderate hypergly cemia augments ischemic brain damage: a neuropathologic study in the rat. Neurology 32:1239-1246

4. Courten-Myers GM, Kleinholz M, Wagner KR, Myers RE 1989 Fatal strokes in hyperglycemic cats. Stroke 20:1707-1715

5. Kushner M, Nencini P, Reivich M, Rango M, Jamieson D, Fazek F, Zimmerman R, Chawluk J, Alavi A, Alues W 1990 Relationship of hyperglycemia early in ischemic brain infarction to cerebral anatomy, metabolism and clinical outcome. Ann Neurol 28:129-135

6. LeMay DR, Gehua L, Zelenock GB, D'Alecy LG 1988 Insulin administration protects neurologic function in cerebral ischemia in rats. Stroke 19:14111419

7. Voll CL, Auer RN 1988 The effect of post-ischemic blood glucose levels on ischemic brain damage in the rat. Ann Neurol 24:638-646

8. Voll CL, Whishaw IQ, Auer RN 1989 Post-ischemic insulin reduces spatial learning deficit following transient forebrain ischemia in rats. Stroke 20:646651

9. Nedergaard M, Diemer NH 1989 Hypoglycemia reduces infarct size in experimental focal ischemia. The influence of plasma glucose on ischemic brain damage. In: Ginsberg MD, Dietrich WD (eds) Cerebrovascular Diseases, Sixteenth Research (Princeton) Conference. Raven Press, New York, pp 259-264

10. Voorhies TM, Rawlinson P, Vannucci RC 1986 Glucose and perinatal hypoxicischemic brain damage in the rat. Neurology $36: 1115-1118$

11. Hattori $H$, Wasterlain CG 1990 Posthypoxic glucose supplementation reduces hypoxic-ischemic brain damage in the neonatal rat. Ann Neurol 28:122-128

12. Fanaroff AA, Martin RJ 1987 Metabolic and endocrine disorders. In: Fanaroff AA, Martin RJ (eds) Neonatal-Perinatal Medicine. CV Mosby, St. Louis, pp 1049-1077

13. Rice JE, Vannucci RC, Brierley JB 1981 The influence of immaturity on hypoxic-ischemic brain damage in the rat. Ann Neurol 9:131-141

14. Towfighi J, Yager JY, Housman C, Vannucci RC 1991 Neuropathology of remote hypoxic-ischemic damage in the immature rat. Acta Neuropathol 81:578-587

15. Lowry OH, Passonneau JV 1972 A Flexible System of Enzymatic Analysis. Academic Press, New York

16. Williamson DH, Mellanby J 1963 D-(-)- $\beta$-hydroxybutyrate. In: Bergmeyer $\mathrm{HU}$ (ed) Methods of Enzymatic Analysis. Academic Press, New York, pp 459-461

17. Moore TJ, Lione AP, Regen DM, Tarpley HL, Raines PL 1971 Brain glucose metabolism in the newborn rat. Am J Physiol 221:1746-1753

18. Cremer JE, Cunningham VJ, Pardridge WM, Braun LD, Olendorf WH 1979 Kinetics of blood-brain barrier transport of pyruvate, lactate and glucose in suckling, weaning and adult rats. J Neurochem 33:439-445

19. Fuglsang A, Lomholt M, Gjedde A 1986 Blood-brain transfer of glucose and glucose analogs in newborn rats. $J$ Neurochem $46: 1417-1428$

20. Hawkins RA, Williamson DH, Krebs HA 1971 Ketone body utilization by adult and suckling rat brain in vivo. Biochem J 122:13-18

21. Cremer JE, Braun LD, Olendorf WH 1976 Changes during development of transport processes of the blood-brain barrier. Biochem Biophys Acta 448:633-637

22. Cremer JE 1982 Substrate utilization and brain development. J Cereb Blood Flow Metab 2:394-407

23. Hellman J, Vannucci RC, Nardis EE 1982 Blood-brain barrier permeability to lactic acid in the newborn dog: lactate as a cerebral metabolic fuel. Pediatr Res 16:40-44

24. Kraus H, Schlenker S, Schwedesky D 1974 Developmental changes of cerebral ketone body utilization in human infants. Hoppe Seylers Z Physiol Chem 355:164-170

25. Diebler MF, Farkas-Bargeton E, Wehrte R 1979 Developmental changes of enzymes associated with energy metabolism and the synthesis of some neurotransmitters in discrete areas of human neocortex. J Neurochem $32: 429-435$
26. Phelps ME, Mazziotta JC, Huang S-C 1982 Study of cerebral function with positron computed tomography. J Cereb Blood Flow Metab 2:113-162

27. Vannucci RC, Lyons DT, Vasta F 1988 Regional cerebral blood flow during hypoxia-ischemia in immature rats. Stroke 19:245-250

28. Altman DI, Young RSK, Yagel SK 1984 Effects of dexamethasone and hypoxic-ischemic brain injury in the neonatal rat. Biol Neonate 46:149-156

29. Diemer NH, Siemkowicz E 1981 Regional neurone damage after cerebral ischemia in the normo- and hypoglycemic rat. Neuropathol Appl Neurobiol 7:217-227

30. Wellens D, Wouters L, Nijkamp FP, De Jong W 1976 Distribution of blood flow supplied by the vertebral artery in rats: anatomical, functional and pharmacological aspects. Experientia 15:85-87

31. Vannucci RC, Hellmann J, Hernandez MJ, Vannucci SJ 1980 Lactic acid as an energy source in perinatal brain. In: Passonneau JV, Hawkins RA, Lust WD, Welsh FA (eds) Cerebral Metabolism and Neural Function. Williams \& Wilkins, Baltimore, pp 264-271

32. Dombrowski GJ, Swiatek KR, Chao K-L 1989 Lactate, 3-hydroxybutyrate and glucose as substrates for the early postnatal rat brain. Neurochem Res 14:667-675

33. Vannucci RC, Vannucci SJ 1978 Cerebral carbohydrate metabolism during hypoglycemia and anoxia in newborn rats. Ann Neurol 4:73-79

34. Kappy MS, Raizada MK 1982 Adult-level insulin binding is present in term fetal rat CNS membranes. Brain Res 249:390-392

35. Kappy M, Sellinger S, Raizada M 1984 Insulin binding in four regions of the developing rat brain. J Neurochem 42:198-203

36. Lowe WL, Boyd FT, Clarke DW, Raizada MK, Hart C, LeRoith D 1986 Development of brain insulin receptors: structural and functional studies of insulin receptor from whole brain and primary culture. Endocrinology 119:25-35

37. Boyd FT, Clarke DW, Muther TF, Raizada MK 1985 Insulin receptors and insulin modulation of norepinephrine uptake in neuronal cultures from rat brain. J Biol Chem 260:15880-15884

38. Raizada MK, Shemer J, Judkins JH, Clarke DW, Masters BA, LeRoth D 1988 Insulin receptors in the brain: Structural and physiological characterization. Neurochem Res 13:297-303

39. Blomqvist $P$, Lindvall $D$, Wieloch $T 1985$ Lesions of the locus coeruleus system aggravate ischemic damage in the rat brain. Neurosci Lett 58:353-358

40. Koide T, Wieloch TW, Siesjö BK 1986 Circulating catecholamines modulate ischemic brain damage. J Cereb Blood Flow Metab 6:559-565

41. Miyauchi Y, Wieloch T, Lindvall O 1989 Noreadrenaline metabolism in neocortex and hippocampus following transient forebrain ischemia in rats: relation to development of selecting neuronal necrosis. J Neurochem 53:408415

42. Kirsch JR, D'Alecy LG 1979 Effect of altered availability of energy-yielding substrates upon survival from hypoxia in mice. Stroke 10:288-291

43. Marie C, Bralet A-M, Gueldry S, Bralet J 1990 Fasting prior to transient cerebral ischemia reduces delayed neuronal necrosis. Metab Brain Dis 5:6575

44. Holowach-Thurston J, Hauhart RE 1989 Ketonemia increases survival of young mice in anoxic as well as hypoxic environments: possible mechanisms of this unexpected finding. Pediatr Res 25:362A(abstr)

45. Lundy EF, Dykstra JD, Luyck B, Zelenock GB, D'Alecy LG 1985 Reduction of neurologic deficit by 1,3-butanediol induced ketosis in Levine rats. Stroke 16:855-860

46. Gueldry SG, Marie C, Rochette L, Bralet J 1990 Beneficial effect of 1,3butanediol on cerebral energy metabolism and edema following brain embolization in rats. Stroke 21:1458-1463

47. Devivo DC, Leckie MP, Agrawal HC 1973 The differential incorporation of $\beta$-hydroxybutyrate and glucose into brain glutamate in the newborn rat. Brain Res 55:485-490

48. Page MA Krebs HA, Williamson DH 1971 Activities of enzymes of ketonebody utilization in brain and other tissues of suckling rats. Biochem J 121:4953

49. Booth RFG, Patel TB, Clark JB 1980 The development of enzymes of energy metabolism in the brain of a precocial (guinea pig) and non-precocial (rat) species. J Neurochem 34:17-25

50. Yager JY, Brucklacher RM, Vannucci RC 1991 Cerebral oxidative metabolism and redox state during hypoxia-ischemia and early recovery in the immature rat. Am J Physiol (in press)

51. Edmond J, Robbins RA, Bergstrom JD, Cole RA, de Vellis J 1987 Capacity for substrate utilization in oxidative metabolism by neurons, astrocytes, and oligodendrolytes from developing brain in primary culture. J Neurosci Res 18:551-561

52. Dahlquist G, Persson B 1976 The rate of cerebral utilization of glucose, ketone bodies, and oxygens: a comparative in vivo study of infant and adult rats. Pediatr Res 10:910-917 